\title{
QUADCOPTER FLIGHT CONTROLLER DESIGN ON THE OTHTT SYSTEM PROTOTYPE (OVER THE HORIZON TARGET TRACKING)
}

\author{
Erpan Sahiri', Supartono², Sigit Purwanto ${ }^{3}$, Rangga Paksi Senggono ${ }^{4}$ \\ 1,3,4 Indonesian Naval Technology College, STTAL Surabaya Indonesia \\ 2Indonesia Defense University, Unhan Jakarta Indonesia \\ bedjofpv@gmail.com
}

\begin{abstract}
The development of drone technology at this time is very rapid with a variety of functions and uses, including use in the military sphere. In this study, researchers made a prototype of a drone that can identify the target while determining the latitude and longitude of the target. This research was carried out because the Navy had defense equipment, a ship that had the ability to shoot missiles. This missile possession is important because in addition to being a deterence effect, modern naval battles are dominated by long-distance warfare or Over The Horizon. In missile fire, accurate intelligence is needed to determine the position of the target. So far what has been done is sending submarines or reconnaissance aircraft. This is very inefficient because in addition to requiring large resources, the risk of losing personnel and material is also very large. To realize this, researchers create a system that can overcome existing limitations. The focus of research conducted by researchers at this time is to create a flight controller on the drone. This system uses the Arduino Mega 2560 PRO Embed as a flight controller that is connected to other parts such as batteries, brushless motors, ESC (Electronic Speed Control) and propeller so that it can move the drone according to operating needs. At the time of testing, vertical flight test, horizontal flight test, pitch and roll control test and altitude control test were carried out. Meanwhile, to get stability when flying, then you need the right PID settings on the flight controller. Based on the test results obtained $K p=7.5, K i=0.045$ and $K d=24$, so that the drone can fly stably. From the test results it can also be concluded that the drone has been able to carry out its basic functions to fly, approach the target and return to the ground station after carrying out the mission.
\end{abstract}

Keywords: Drone, Control, Stability.

\section{INTRODUCTION}

In terms of its range, the missile owned by the Navy can be said to be a very reliable missile. For example, the ownership of Yakhont missiles with a range of up to $350 \mathrm{~km}$, the Navy can provide deterence effect to any group or country that wants to disrupt the sovereignty of the Republic of Indonesia. But until now, the ability of such a capable missile has not been matched by detection sensor equipment, in this case radar, which can provide target data that is at a considerable distance. This results in the ability of the missile that can reach targets up to a distance of $350 \mathrm{~km}$ is not optimal. Therefore we need an equipment or vehicle as an "extension of the eye" of the KRI to detect targets so that later can be used as a reference in carrying out missile shooting. During this time before carrying out missile fire, submarines were sent as an element of reconnaissance of the target. This submarine will later provide target data to $\mathrm{KRI}$ as a shooting reference. Submarine delivery certainly requires significant resources coupled with great risk. From the above problems, researchers have an idea to create a vehicle that can replace the submarine's role in providing target data to $\mathrm{KRI}$ as a missile shooting reference.

The vehicle that will be created is a UAV that uses the OTHTT (Over The Horizon Target Tracking) system. This UAV will provide data in the form of the latitude longitude of the target processed from the latitude and longitude data of the UAV itself. In addition, the UAV will also provide a visualization of the target so that it can convince KRI that the intended target is really the target to be paralyzed. This UAV will communicate continuously (real time) with the $\mathrm{KRI}$ in order to provide accurate data so as to provide high accuracy at the time of the shooting. All of this is an effort to minimize the risk of submarine resource use in a military operation carried out by the task force by applying the Design of the Target Tracker to the Image Processing Base of the OTHTT (Over The Horizon Target Tracking) Prototype System.

\section{LITERATURE REVIEW 2.1 Quadcopter Definition. \\ Quadcopter is one type of unmanned vehicle that has four motors equipped with four}


propellers on each motor used for flying and maneuvering.

Each rotor (propeller and motor drive) produces lift and has the same distance to the center of mass of the vehicle. With the lift of each rotor is more than a quarter of the overall weight, allowing the quadcopter to fly. The speed of the quadcopter depends on the power of the motor and the weight of the quadcopter itself.

To avoid the moment of turning in the body, the direction of rotation of the propeller on each rotor is different. There are 2 rotors that move clockwise $(\mathrm{CW})$ and 2 rotors that move counter-clockwise (CCW).

The most commonly used configuration is the X-quadcopter. When the quadcopter is flying and hovering in air (hovering) the rotational speed on each rotor is the same. When the quadcopter moves forward, 2 propellers or propellers behind will spin faster so that the quadcopter's body will tilt forward. The thrust produced by the four propellers will have upward and forward force components so that the quadcopter will be pushed forward while maintaining its height.

The picture below is an illustration of the movement which is affected by the speed of the propeller.

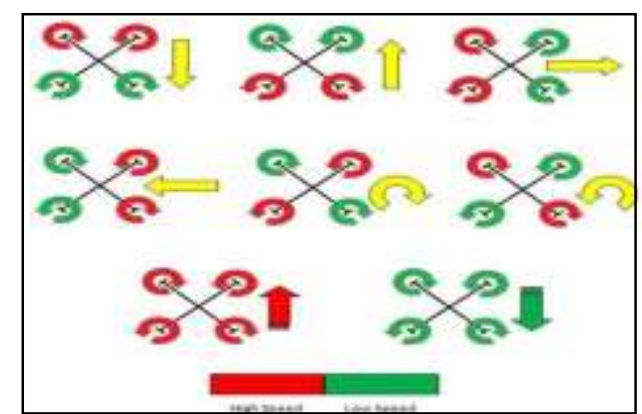

Figure 2.1 Basic movement of a quadcopter motor.

\section{$2.2 \quad$ Flight Controller.}

Flight controller

is a collection of various components and sensors that function to keep the drone or quadcopter in balance and can be controlled.

Quadcopter flight controller has a balance sensor in the form of a gyro and accelerometer. Some of the newest flight controllers even have air pressure sensors (barometers and magnetometers) and gps. The barometer sensor functions to maintain the height of the quadcopter at a certain height then the magnetometer and gps are used to maintain orientation, autopilot and failsafe features.

Now there are many types of flight controllers that have the same hardware components, but each developer (developer) of the flight controller has its own algorithm in programming so that it will produce different flight characteristics.

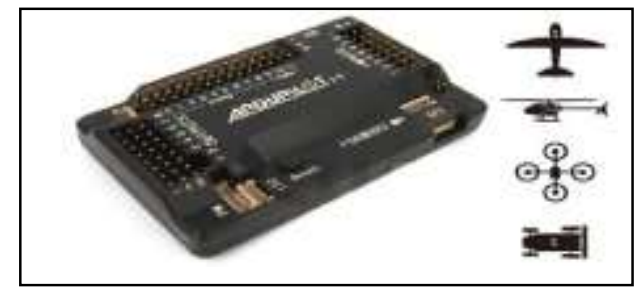

Figure Error! No text of specified style in document..2 Flight Controller

\subsection{Mega 2560 Pro Embed microcontroller.}

In making this final project, one product that is compatible with Arduino Idea, known as Mega 2560 Pro Embed, will be used.

Mega 2560 pro embed has 54 digital pins that can be used as input or output. Of these 54 pins, 15 of them can be used as pulse width modulation output (pwm), have 16 analog input pins, 4 uart pins that function as hardware serial ports, a $16 \mathrm{mhz}$ crystal oscillator, a female jack for USB connections, female adapter jack and a reset button. In this study the microcontroller ic used was atmega 2560. The atmega 2560 microcontroller was square with a number of pins of 100 pins. The Atmega 2560 has the ability to execute program instructions in one single clock cycle, so the Atmega 2560 is able to optimize power consumption compared to program processing speed.

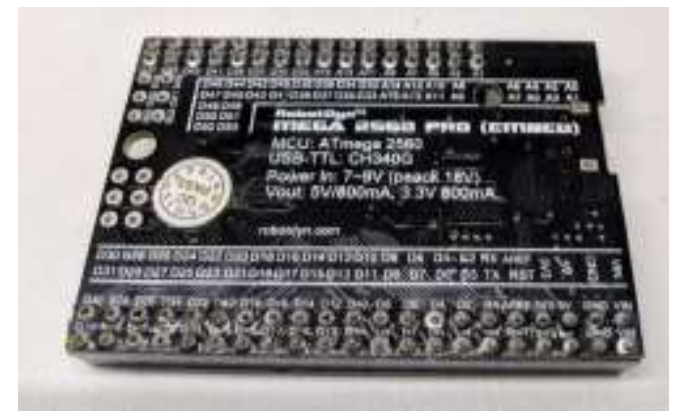

Figure Error! No text of specified style in document..3 Mega 2560 PRO Embed

\subsection{PID Control}

The existence of a controller in a control system has a major contribution to the behavior of the system. In principle, it is caused by the irreversible components of the system. That is, plant characteristics must be accepted as they are, so that changes in system behavior can only be done through the addition of a sub-system, the controller.

One of the tasks of the controller is to reduce the error signal, which is the difference between the setting signal and the actual signal. 
This is in accordance with the purpose of the control system is to get the actual signal always (desired) the same as the control signal. The faster the reaction of the system follows the actual signal and the smaller the error that occurs, the better the performance of the control system applied.

If the difference between the adjustment value and the output value is relatively large, a good controller should be able to observe this difference to immediately produce an output signal to affect the plant. Thus, the system quickly changes the plant output until a difference is obtained between the settings and the smallest possible amount.

Good system capability is the goal of controlling the altitude of the UAV paraglider model which includes settling time, research, maximum overshoot and steady state error. Defining performance criteria based on system dynamic response graphs is shown in the figure below.

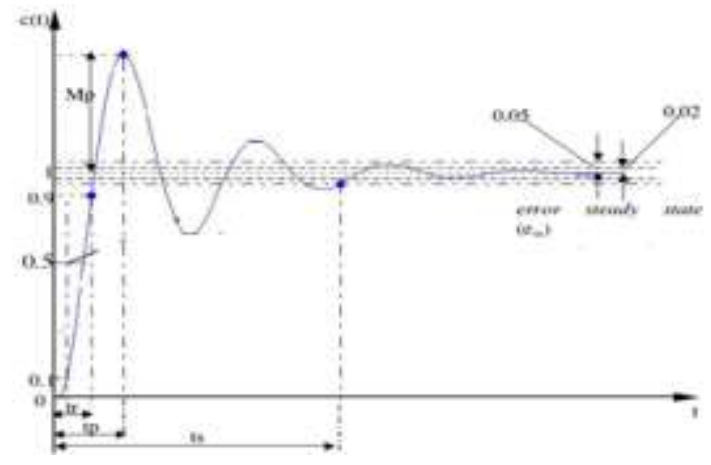

Figure 2.4 Criteria for system performance.

\section{MATERIALS AND METHODS}

2.1 Design of System

An overview of the system created in this final project can be seen in Figure 3.1.

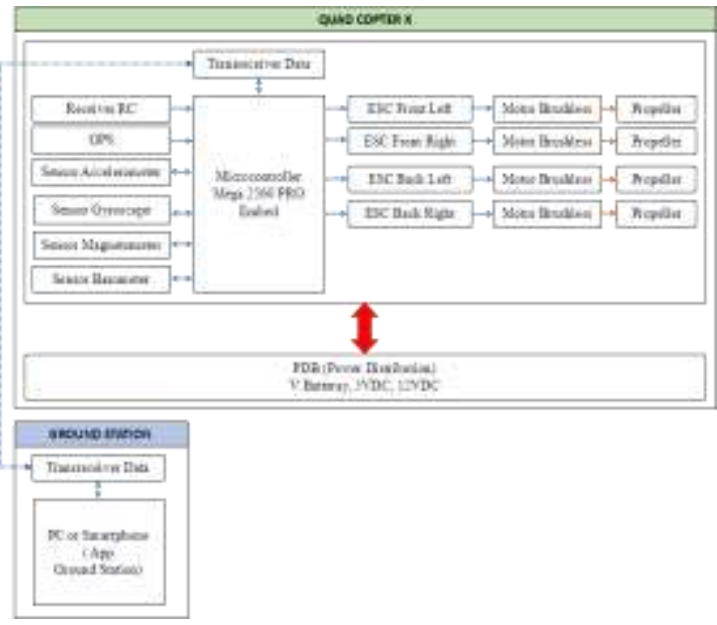

Figure 3.1 UAV tracker design
Based on Figure 3.1 it can be seen that the system design includes the design of quadcopter hardware and software. Hardware design includes manufacturing flight controller hardware, sensor selection, hardware power distribution, selection of ESC (Electronic Speed Controller), motors, propellers and telemetry monitoring hardware both in quadcopter and ground station. Software design includes control systems, data telemetry systems, and ground station software. A ground station consists of a computer or smartphone, telemetry, and ground station software. Ground station software is used as a monitoring system for quadcopter data, log data, changing PID control parameters, and changing flight mode. In the quadcopter flight controller uses a microcontroller to access the accelerometer sensor, gyro, magnetometer, barometer, GPS and data telemetry systems. While the telemetry component is used to connect quadcopter and ground station data.

Whereas specifically for the flight controller on a quadcopter system that uses an IMU (Inertial Measurement Unit) sensor based on the ATmega 2560 Microcontroller consisting of 3 parts namely the input unit, processor, and output unit. The input unit consists of an IMU receiver and sensor, the processing unit is the Mega 2560 PRO Embed microcontroller and the output unit is the ESC (Electronic Speed Controller) and brushless motor. Parts of the flight controller can be seen as in the chart below.

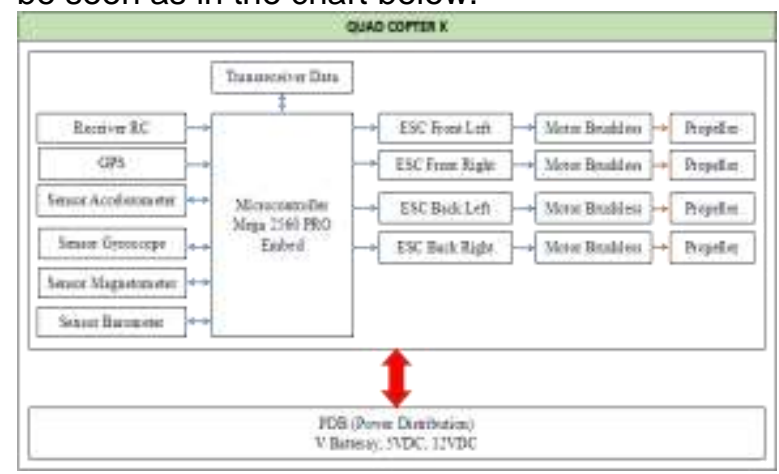

Figure 3.2 Flight controller block diagram with Mega 2560 PRO Embed

From Figure 3.2 it can be seen that the main system is regulated and controlled by Mega 2560 PRO Embed, which gets input from the RC receiver, accelerometer sensor, gyroscope, magnetometer, barometer, GPS meter as reference data for motor movements.

\section{System Testing}

This section will discuss the testing and analysis of systems based on planning. Testing: - Testing the flight controller circuit with the Embed Mega 2560 PRO, which consists of several sensors namely the accelerometer and 
gyro sensors, a barometer that functions as a height detection quadcopter, and motor brussles. - System-wide testing, including system PID testing and pitch, roll stability and vertical, horizontal flight testing on quadcopter.

\subsection{Hardware Testing.}

Hardware testing includes brushless motor testing and the Mega circuit which includes testing of the L3G4200D gyro sensor, the ADXL345 accelerometer sensor and the barometer sensor. The purpose of this test is to find out whether the accerometer, gyro, compass and barometer sensors are working well. While the tools and materials used are the flight controller that has been installed ADXL345 accellerometer sensor, L3G4200D gyro, and BMP085 barometer sensor. For testing the method is as follows: First, connect the flight controller with a PC, then enter the program into the flight controller, then open the Multiwii WinGUI application. The next step is to observe the gyro sensor data by moving the gyro sensor on the $x, y$ and $z$ axis in sequence, observing the accellerometer sensor data by moving the accelerometer sensor on the $\mathrm{x}, \mathrm{y}$ and $\mathrm{z}$ axis sequentially and observing the barometer sensor data by bringing the barometer sensor up on skyscraper.

a. Testing the L3G4200D gyro sensor.

The L3G4200D is a two axis gyro sensor used in quadcopter. This sensor is useful for detecting pitch and roll angle movements, so that it will be able to be used to control the stability of the $x$ and $y$ axes. The purpose of this experiment is to determine the performance of the L3G4200D gyro sensor on the $x$-axis and y-axis, so we can find out the characteristics of the sensor and also know the stability response of the L3G4200D sensor to be applied to the quadcopter. Testing is done by moving the gyro sensor with a certain speed. The following are the results of the L3G4200D sensor data on the $x$-axis and $y$-axis, as can be seen in Figure 4.10 is the testing of the gyro sensor on the $x$-axis and Figure 4.1 on the y-axis.

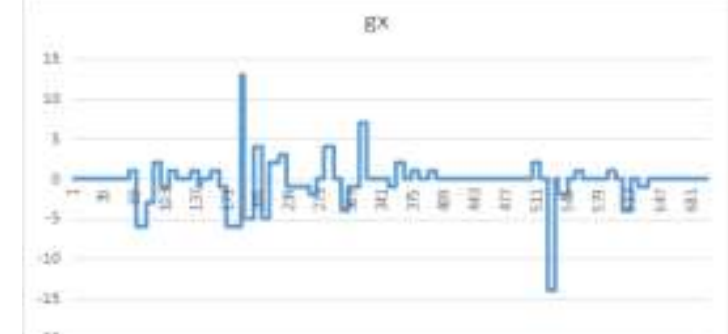

Figure 4.1 X-axis Gyro L3G4200D Sensor Response.

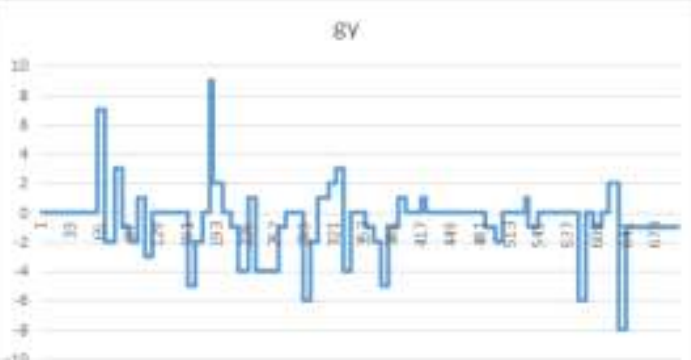

Figure 4.2 Y-axis Gyro L3G4200D Sensor Response.

The purpose of this experiment is to obtain information about the L3G4200D on the zaxis, so we can find out the characteristics of the sensor and also know the stability response of the L3G4200D sensor to be applied to the quadcopter. The following as shown in Figure 4.3 is the result of L3G4200D sensor data on the zaxis.

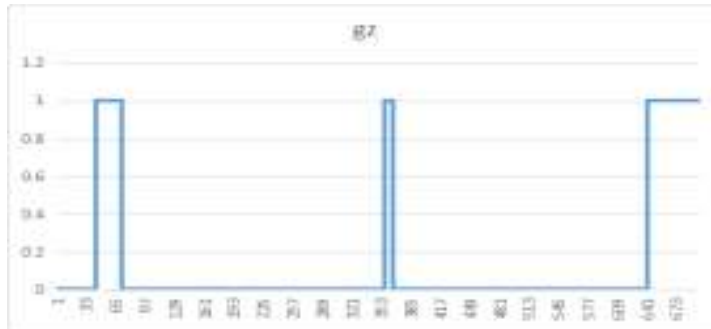

Figure 4.3 Z-axis L3G4200D gyro sensor data.

b. Testing the ADXL 345 accelerometer sensor.

The ADXL345 sensor is a three axis accelerometer sensor, this sensor is used to detect the linearity of the $x, y$ axis and $z$ axis so that it will provide stability to each axis of pitch, roll and yaw.

1) Testing the ADXL $345 \times$ axis accelerometer sensor.

The $x$-axis testing is done by giving a member of the motion response and taking data from the ADXL345 accelerometer sensor, this is done to determine the characteristics of the sensor and can determine the response of the sensor, as shown in Figure 4.4.

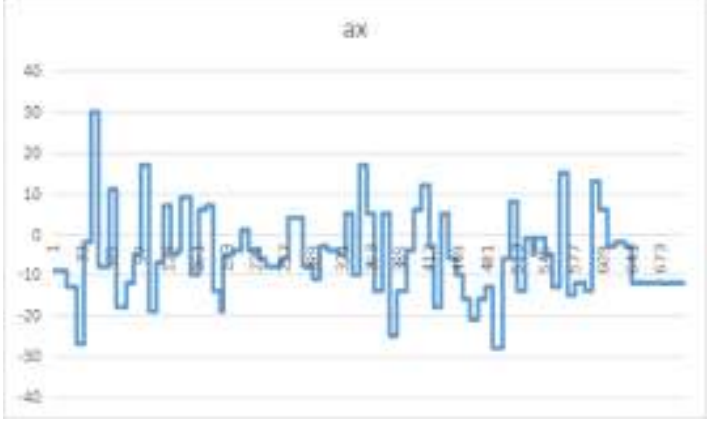


Figure Error! No text of specified style in document..41 Respon Sensor

Accelerometer ADXL345 sumbu- $X$

From the data in Figure 4.4 of the $x$-axis ADXL345 Accelerometer sensor above, it can be seen that the Accelerometer ADXL345 sensor can read linear acceleration.

2) Testing the ADXL 345 y axis accelerometer sensor.

$Y$ axis testing is done by member response to motion and retrieve data from the ADXL345 Accelerometer sensor, this is done to determine the characteristics of the sensor and can determine the response of the sensor, as shown in Figure 4.5 which is the test result of the Accelerometer sensor on the $y$-axis

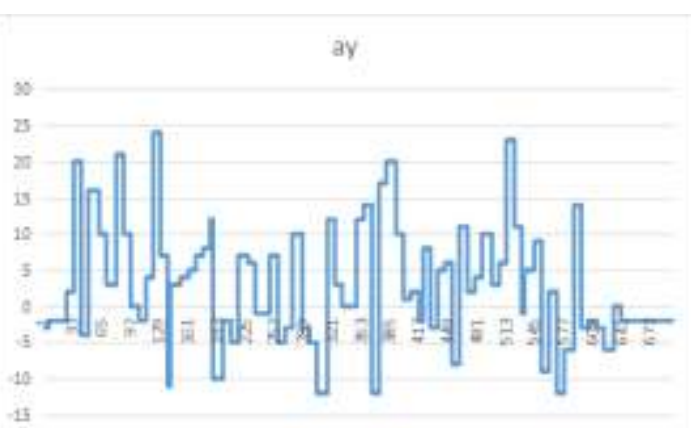

Figure Error! No text of specified style in document..52 Respon Sensor

Accelerometer ADXL345 sumbu-y.

3) Testing the ADXL $345 \mathrm{z}$ axis accelerometer sensor.

$Z$ axis testing is done by member response to motion and retrieve data from the ADXL345 Accelerometer sensor, this is done to determine the characteristics of the sensor and can determine the response of the sensor, as shown in Figure 4.15 is the response of the Accelerometer sensor on the z-axis.

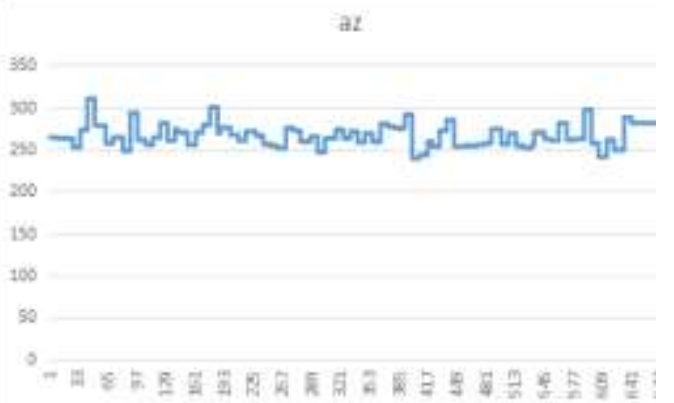

Figure 4.6 Accelerometer ADXL345 Sensor Response $z$ axis.

c) Testing the BMP085 barometer sensor.
The BMP085 sensor is a sensor to measure the altitude of the quadcopter so that the altitude data can be observed.

1) Testing the barometer sensor in a still condition.

Barometer sensor testing at rest is done by placing the barometer sensor at the same height, this is done to determine the characteristics of the sensor and can determine the response of the sensor, as shown in Table 4.1

Table 4.1 Barometer height data

\begin{tabular}{|c|c|c|}
\hline $\begin{array}{l}\text { Reference High } \\
\text { (m) }\end{array}$ & $\begin{array}{l}\text { High from } \\
\text { datasensor } \\
(\mathrm{m})\end{array}$ & Error (m) \\
\hline 0 & 0 & 0 \\
\hline 0 & 0 & 0 \\
\hline 0 & 0.5 & 0.5 \\
\hline 0 & 0.3 & 0.3 \\
\hline 0 & 0 & 0 \\
\hline 0 & 0.3 & 0.3 \\
\hline 0 & 0 & 0 \\
\hline 0 & 0.3 & 0.3 \\
\hline 0 & -0.4 & -0.4 \\
\hline 0 & 0 & 0 \\
\hline 0 & 0.2 & 0.2 \\
\hline 0 & -0.1 & -0.1 \\
\hline 0 & 0.3 & 0.3 \\
\hline 0 & 0.2 & 0.2 \\
\hline 0 & 0.7 & 0.7 \\
\hline 0 & 0.3 & 0.3 \\
\hline 0 & 0 & 0 \\
\hline 0 & 0.4 & 0.4 \\
\hline 0 & 0.1 & 0.1 \\
\hline 0 & 0.2 & 0.2 \\
\hline
\end{tabular}

Presentation of data in graphical form is as follows

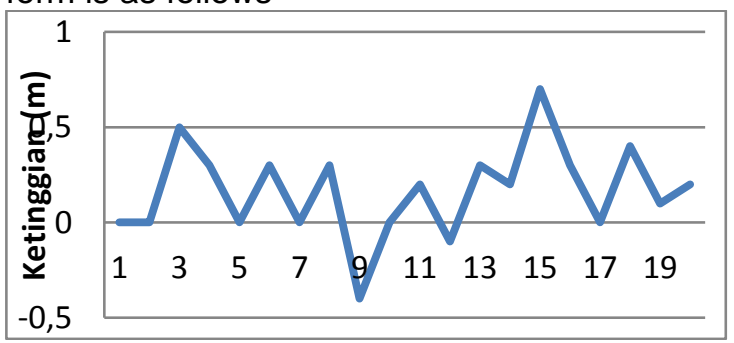

Figure 4.7 Changes to the barometer data at rest.

2) Testing barometer sensors with different heights.

Barometer sensor testing by placing the barometer sensor at different heights, this is done to determinethe 
characteristics of the sensor height reading error, as shown in Table 4.2

Table 4.2 Sensor height reading error values.

\begin{tabular}{|c|c|c|}
\hline $\begin{array}{c}\text { Reference } \\
\text { High }(\mathrm{m})\end{array}$ & $\begin{array}{c}\text { High from } \\
\text { datasensor }(\mathrm{m})\end{array}$ & $\begin{array}{c}\text { Error } \\
(\mathrm{m})\end{array}$ \\
\hline 0 & 0.2 & 0.2 \\
\hline 1 & 0.7 & -0.3 \\
\hline 2 & 2.5 & 0.5 \\
\hline 3 & 3.3 & 0.3 \\
\hline 4 & 4.1 & 0.1 \\
\hline 5 & 5.3 & 0.3 \\
\hline 6 & 6.2 & 0.2 \\
\hline 7 & 6.7 & 0.3 \\
\hline 8 & 8.4 & 0.4 \\
\hline 9 & 9.5 & 0.5 \\
\hline 10 & 10.2 & 0.2 \\
\hline
\end{tabular}

In table 4.2 the BMP085 sensor test data is presented at different heights, the results obtained with a maximum error of $0.5 \mathrm{~m}$.

3.2 Overall System Testing.

The overall system test includes testing the pitch, roll and altitude control systems while flying. This test is carried out to ensure the control system is working properly. One of the manual flight test drawings is shown in Figure 4.8.

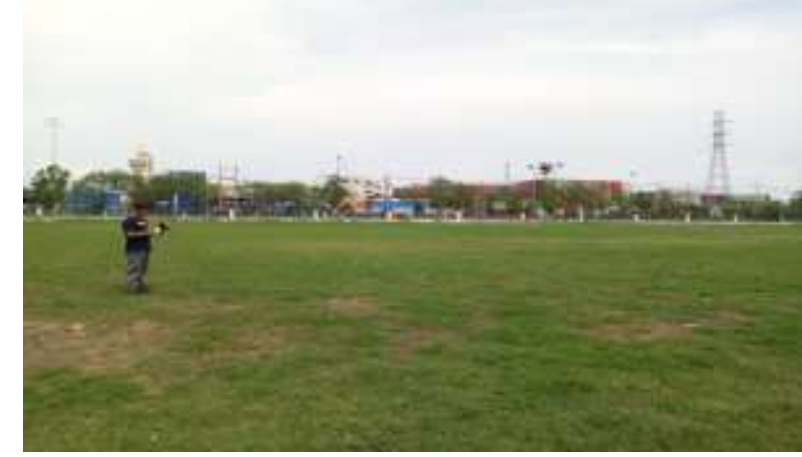

Figure 4.8 Flight Testing Pitch

The first stability effect of the quadcopter is the output pitch. The pitch allows the quadcopter to move forward or backward. So the motor that affects the motor 3 (front) and 4 (rear). Pitch Control is the output of the entire control system which includes PID on the $y$-axis sensor gyro and the $x$-axis accelerometer sensor.

In this pitch control test, data is taken from the PID control output of the pitch control and the raw data of the $y$-axis gyro sensor and the $x$-axis accelerometer sensor, as the output of the pitch control, as shown in Figure 4.9.a

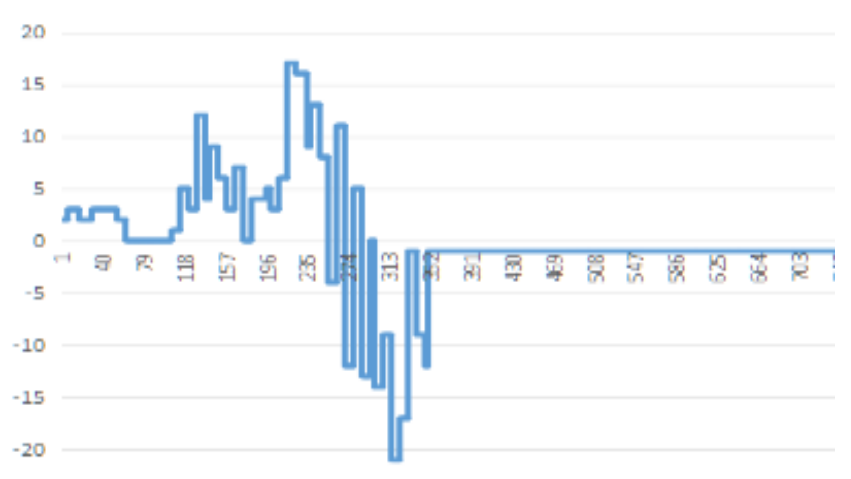

Figure 4.9 Pitch Data Control Graph.

From the pitch control data graph in Figure 4.9 it can be seen that the pitch control system has worked well, both under normal conditions and when given pressure disturbances. The control system is a PID output from the $x$-axis accelerometer sensor and the $y$ axis gyro sensor with a set point of 0 .

A Roll Control Testing.To maintain the stability of the quadcopter in a horizontal position, there are 2 angles that affect the roll angle and pitch angle. In this section we will show a simulation of the change in roll angle. To change the roll angle can be done by changing the speed of the left motor (motor 1) and right (motor 2) if the right motor is increased by $\mathrm{x}$ then the left motor is reduced by $x$ and vice versa. Roll control is the output of the entire control system which includes PID on the $x$-axis of the gyro sensor and the $y$ axis of the accelerometer sensor.

In this roll control test, data is taken from the PID control output of the roll control and the raw data of the $x$-axis gyro sensor and the $y$-axis accelerometer sensor, as the output of the roll control, as shown in Figure 4.10.

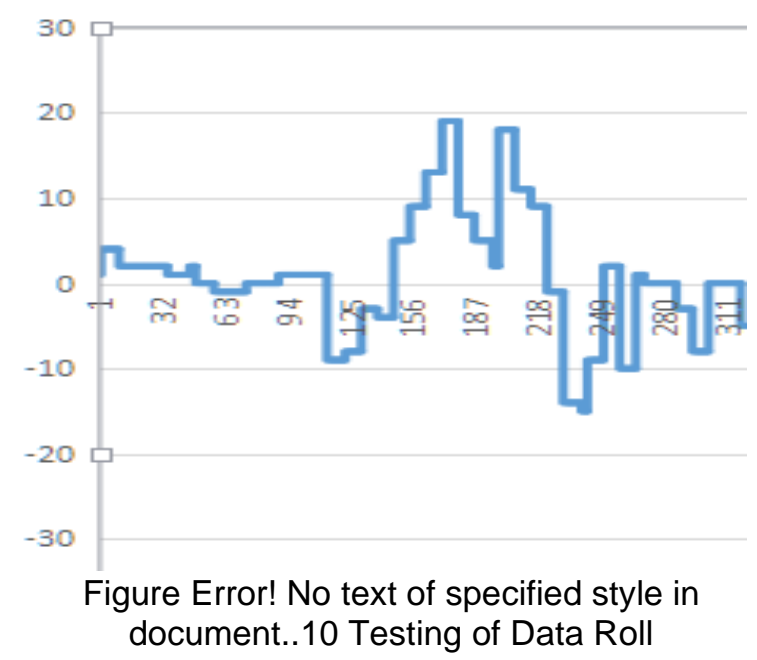

From Figure 4.10 which is a data roll test, it can be seen the data output and input of the roll 
control, the input roll control is the data from the roll angle error. Roll control system can be seen that the system has worked well, both when normal conditions and when given a distraction in the form of pressure. The control roll system is the PID output of the $y$-axis accelerometer sensor and the $y$-axis gyro sensor with a set point of 0 .

a. Testing Altitude Control.

Altitude on quadcopter can occur if visually the quadcopter is flying and still does not stick to ground, theoretically the upward force received by the quadcopter is the same as its gravity. So to get an upward force that is equal to the weight force, the propeller rotation must be able to reach the minimum point of rotation speed.

b.

Tuning PID.

In this PID tuning experiment, tuning is done using an experimental method, where testing is carried out by flying a quadcopter to be able to maintain altitude, this is done to find out whether the PID parameters have worked well or not. In this mode the BMP085 Barometer sensor becomes the main reference in the control system, the altitude control system uses PID control. In this test, Holybro V3 Telemetry Radio $500 \mathrm{~mW} 433 \mathrm{MHz}$ is used as telemetry data transmission, following the steps of tuning the PID dick. PID tuning is done using a structured method or often called experimental.

1) First quadcopter is turned on or connected to the battery.

2) Holybro module is connected to the laptop and connected to Multiwii WinGUI. 3) After Multiwii WinGUI is connected to the quadcopter, it is first seen that all the data is really good or not.

4) After all the sensor data is in a good taste then the tunning is done, first the tunning of the proposonal control is done first.

5) Increase the value of $\mathrm{Kp}$ until the response oscillates around the set point. But it should be noted, the correction of the roll and pitch angle and height on the quadcopter must be fast and precise so that the response expected at this step must be appropriate

6) To reduce the oscillation, add KD with a certain value so that if observed the response occurs on the quadcopter until it is stable and more responsive

7) After Kp and KD tunning is considered sufficient then the $\mathrm{Ki}$ tuning is done, $\mathrm{Ki}$ control functions to eliminate the steady state error, but it should be noted if the response is too large the ki will slow.

8) Experiments 5,6 and 7 were conducted by flying a quadcopter, and looking at sensor parameters to determine the response of the PID tuning.

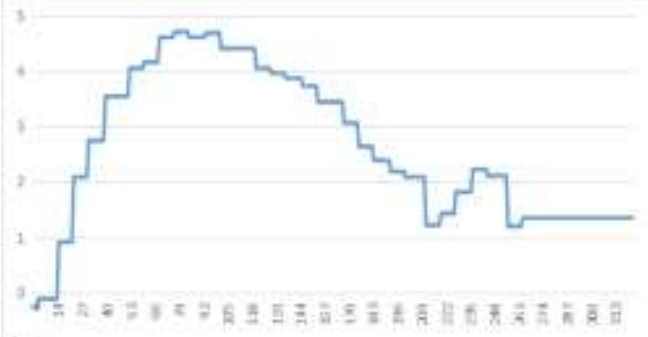

Figure Error! No text of specified style in document..11 Control Altitude Hold

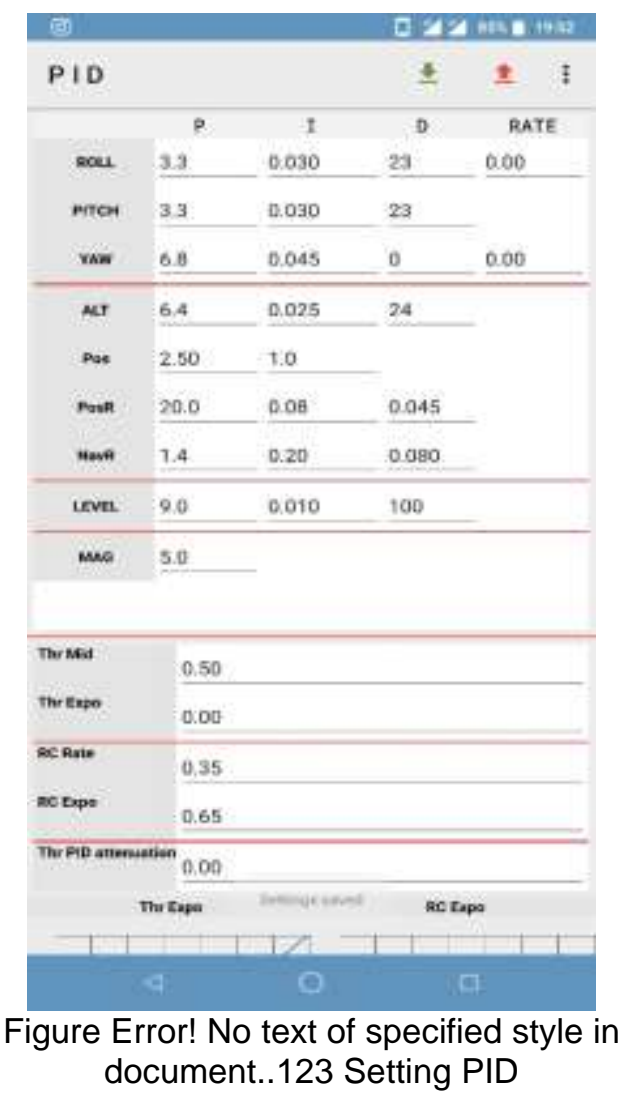

From the results of the first PID tuning where $\mathrm{Kp}=6.4, \mathrm{Ki}=0.025$ and $\mathrm{Kd}=24$ the quadcopter response is still felt slow and oscillation occurs, then the second tuning is performed, as can be seen in Figure 4.13.

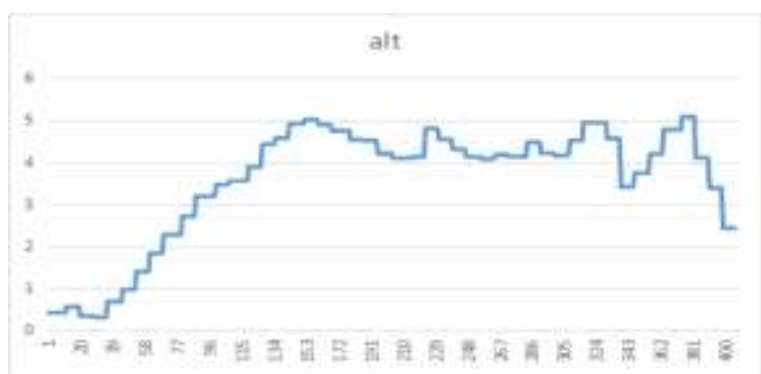

Figure 4.13 Altitude Hold control chart with tuning values $\mathrm{Kp}=7.5, \mathrm{Kd}=0.045$ and $\mathrm{Kd}=24$ 


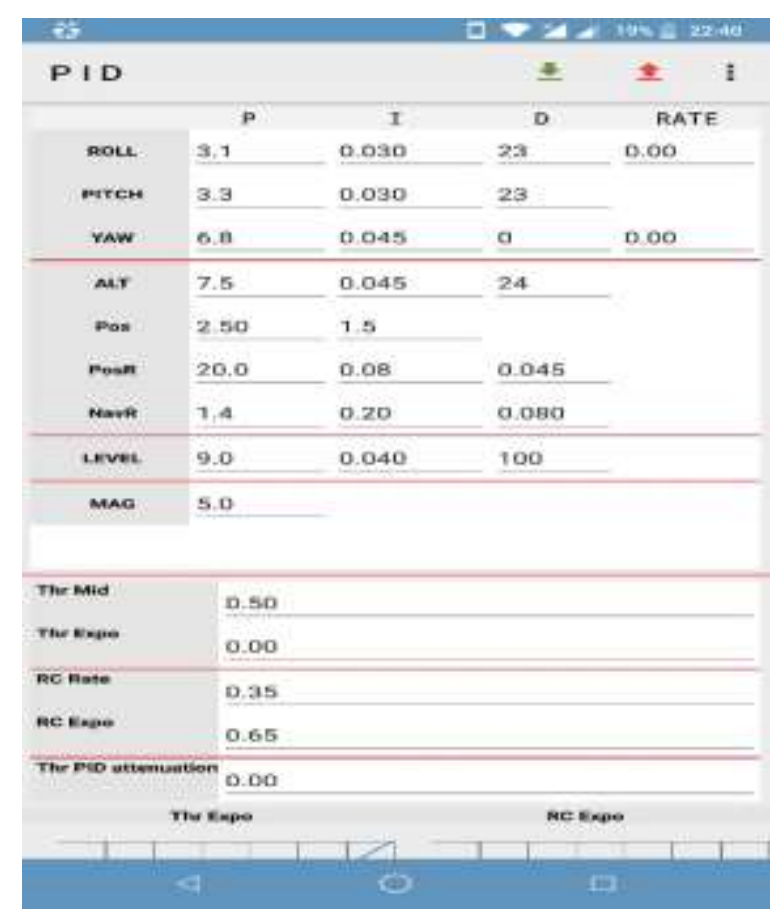

Figure Error! No text of specified style in document..14 PID Setting

From the quadcopter testing experiment with tuning. Data can be analyzed that the PID control parameters can be adjusted to obtain quadcopter stability control, and to be able to maintain altitude, in the first test, the quadcopter is tested to maintain a flight height of about 4 to 5 meters but high oscillation occurs. Then the second tuning, quadcopter flew about 3 to 4 meters, there was a little oscillation compared to before. Then the tuning of the two quadcopter was tested to fly at an altitude of about 4 to 5 meters like the first flight, apparently the quadcopter could maintain altitude better than the second tuning.

a. Quadcopter Flying Speed Testing.

1) Vertical Speed Testing

In this test, a vertical quadcopter speed was tested. In the first experiment the data collection was carried out at a vertical speed with a height sensor using BMP-085 and a time gauge using a stopwatch application from a smartphone.

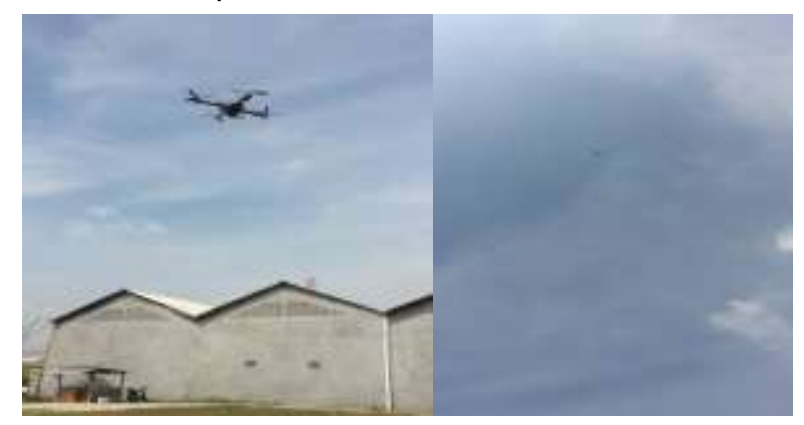

Figure 4.15 Vertical speed test
The results of the vertical flight speed test can be seen in the table below:

Table 4.3 Vertical flight speed

\begin{tabular}{|c|l|l|l|}
\hline No & $\begin{array}{c}\text { High } \\
\text { (meter) }\end{array}$ & $\begin{array}{c}\text { Time } \\
(\text { second) }\end{array}$ & $\begin{array}{c}\text { Velocity } \\
(\mathbf{m} / \mathbf{s})\end{array}$ \\
\hline 1 & 5 & 3,25 & 1,53 \\
\hline 2 & 10 & 2,95 & 1,69 \\
\hline 3 & 15 & 2,15 & 2,32 \\
\hline 4 & 20 & 2,23 & 2,24 \\
\hline 5 & 25 & 2,24 & 2,23 \\
\hline 6 & 30 & 2,39 & 2,09 \\
\hline 7 & 35 & 2,56 & 1,95 \\
\hline 8 & 40 & 2,87 & 1,74 \\
\hline 9 & 45 & 2,50 & 2,00 \\
\hline 10 & 50 & 2,67 & 1,87 \\
\hline \multicolumn{2}{|l|}{ For }
\end{tabular}

respect to time can be seen in the image below:

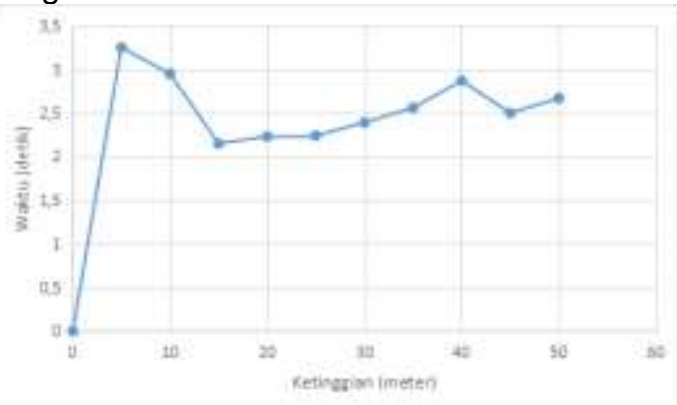

Figure 4.16 Height of time graph.

As for the vertical speed graph can be seen as shown below:

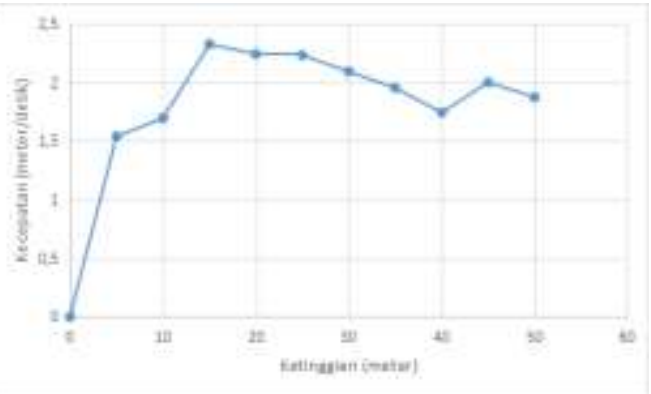

Figure 4.17 Vertical speed graph.

From the experimental data in Figure 4.17 it can be seen the speed of the quadcopter when flying vertically, with an average speed of $1.78 \mathrm{~m} / \mathrm{s}$.

2) Horizontal Speed Testing

This time, the horizontal quadcopter speed testing was conducted. In this experiment, data retrieval at horizontal speed uses a soccer field as a reference to the horizontal distance that has been taken, and the time gauge uses a stopwatch 


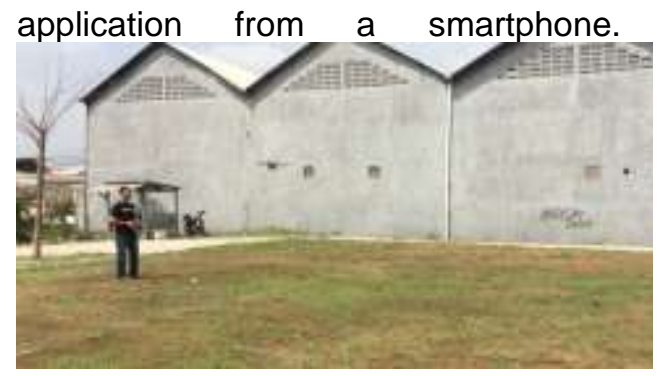

Figure 4.18 The position of the horizontal speed test start.

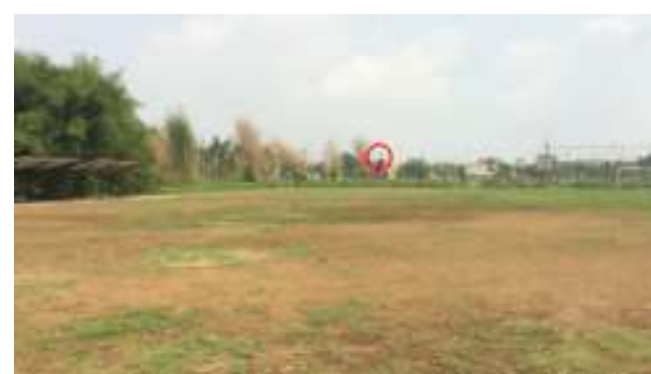

Figure 4.19 Position finish horizontal speed test.

From the experimental results the following data can be obtained:

Table 4.4 Horizontal flight speeds

\begin{tabular}{|l|l|l|}
\hline $\begin{array}{l}\text { Distanca } \\
\text { (meter) }\end{array}$ & $\begin{array}{l}\text { Time } \\
\text { (second) }\end{array}$ & $\begin{array}{l}\text { Velocity } \\
\text { (m/second) }\end{array}$ \\
\hline 0 & 0 & 0 \\
\hline 120 & 9,99 & 12,12 \\
\hline 240 & 11,06 & 10,84 \\
\hline
\end{tabular}

For a graph of distance to time can be seen as shown below:

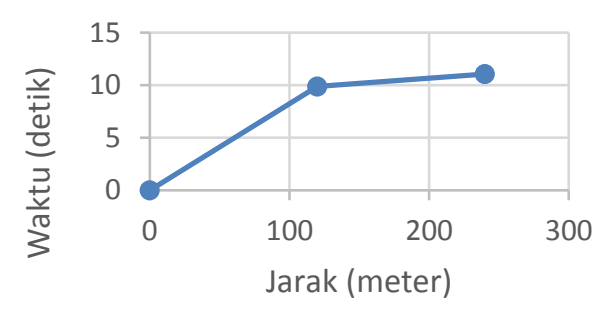

Figure 4.20 Graph of distance to time.

As for the velocity graph against time can be seen as shown below:

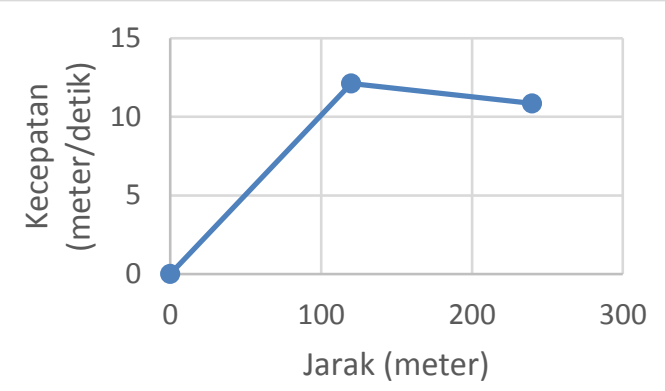

Figure 4.21 Graph of speed with time

b. Angular Velocity Testing.

This time the quadcopter angular velocity testing was conducted. In this experiment the retrieval of data at angular velocity uses a magnetometer sensor as a reference angle that has been taken, and the time gauge uses a stopwatch application from asmartphone.

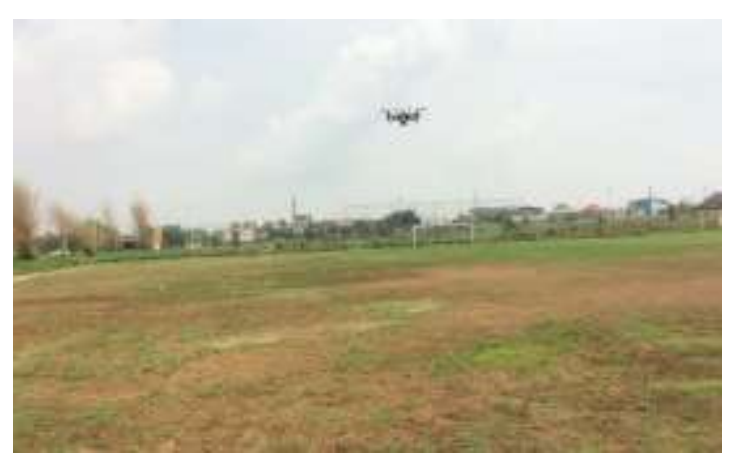

Figure 4.22 Starting position of the angular velocity test.

The results of the above experiments can be seen in the table below:

Table 4.5 Angular velocity

\begin{tabular}{|l|l|l|}
\hline $\begin{array}{l}\text { Angle } \\
\text { (degree) }\end{array}$ & $\begin{array}{l}\text { Waktu } \\
\text { (Second) }\end{array}$ & $\begin{array}{l}\text { Velocity } \\
\text { (degree/second) }\end{array}$ \\
\hline 0 & 0 & 0 \\
\hline 360 & 3,35 & 120,12 \\
\hline
\end{tabular}

\section{CONCLUSIONS AND SUGGESTIONS 4.1 Conclusions}

After carrying out a series of research from the design of the tool to the testing of the tool, the researcher reaches the following conclusions:

a. $\quad$ Flight controller for quadcopter can be implemented using the ATmega 2560 microcontroller, which in this thesis uses the Mega 2560 PRO Embed board. By creating a flight controller itself has advantages in terms of flexibility. The flexibility in question is that the flight controller has the ability to be 
independently developed and the addition of features in certain applications. In the design of quadcopter 4 the main parts are mechanics, electronic hardware, control systems and software. These four parts must be well made to ensure the quadcopter can function properly. The ability of the quadcopter with the flight controller that was made can work for flying purposes but needs to be developed so that it can work well.

b. Flight controller using Arduino Mega 2560 PRO Embed on this quadcopter can achieve stability when flying by using the values of $\mathrm{Kp}=7.5, \mathrm{Ki}$ $=0.045$ and $\mathrm{Kd}=24$ based on experimental results. The stability of this quadcopter is very important in supporting the fundamental functions of this prototype OTHTT system.

\subsection{Suggestions}

a. This research is still in the form of a prototype design. To be used in the actual field of work, it is necessary to increase the capability of the quadcopter. These capabilities include increased flight time, increased accuracy of sensors such as GPS, altimeter and compass.

b. The researcher can then add the waypoint feature and the ability to follow targets based on the target tracking data obtained from the camera tracker integrated with the flight controller so that it can give an advantage to the drone to carry out operational tasks in the actual terrain.

\section{ACKNOWLEDGEMENT}

The authors greatly acknowledge the support from STTAL Surabaya Indonesia for providing the necessary resources to carry out this research work. The authors are also grateful to the anonymous reviewers and journal editorial board for their many insightful comments, which have significantly improved this article.

\section{REFERENCES}

Akbar, Habibi Ghani. 2013. Perancangan Dan Analisis Otomasi Sistem Kendali Quadcopter Melalui Koordinat Dengan Global Positioning System Tracker. Bandung.

Bresciani, Tommaso. 2008. Modelling, Identification and Control of a Quadrotor
Helicopter. Department of Automatic Control, Lund University.

Firdaus, Bagus K. 2011. Aplikasi Accelerometer Sebagai Kendali Stabilizer Quadcopter. Jurnal Politeknik Elektronika Negeri Surabaya. Institut Teknologi Sepuluh Nopember (ITS) Surabaya.

Fowers, G. 2008. Stabilization and Control of $A$ Quad-Rotor Micro-UAV Using Vision Sensors, Thesis, Brigham Young University.

Kusuma, Whanindra. 2012. Perancangan Dan Implementasi Kontrol PID Pada Pengendalian Auto Take off Quadcopter UAV. Institute Teknologi Sepuluh November,Fakultas Teknologi Industri.Surabaya.

Lema, Risha Anugrah N. 2016. Flight Controller Pada Sistem Quadcopter Menggunakan Sensor Imu (Inertial Measurement Unit) Berbasis Mikrokontroler Atmega 2560. Univeritas Sanata Dharma.

Peter O, Basta. 2012. Quadcopter Flight. California State University, Northridge.

Rangku, Muhammad Syahrizal. 2014. Laporan Akhir : Aplikasi GPS Pada Quadcopter Sebagai Pengontrol Hold Position. Politeknik Negeri Sriwijaya. Palembang.

Tamba, Antonius Handika. 2014. Laporan Akhir : Pengontrolan Motor Brushless Pada Quadcopter Dengan Menggunakan Electronic Speed Control (ESC). Politeknik Negeri Sriwijaya. Palembang. 